\title{
Ocular melanoma incidence rates and trends in the United States, 2001-2016
}

\author{
MaryBeth B. Culp $\mathbb{1}^{1} \cdot$ Vicki Benard ${ }^{2} \cdot$ Nicole F. Dowling ${ }^{2}$. Jessica King ${ }^{2} \cdot$ Hua Lu $^{3} \cdot$ Chandrika Rao $^{4} \cdot$ Lia C. Scott $^{2}$. \\ Reda Wilson ${ }^{2} \cdot$ Manxia $\mathrm{Wu}^{2}$
}

Received: 12 March 2020 / Revised: 25 March 2020 / Accepted: 8 April 2020 / Published online: 29 April 2020

(c) The Royal College of Ophthalmologists 2020

\section{To the Editor:}

Ocular melanoma is a rare form of melanoma (less than $5 \%$ of melanoma cases) arising from melanocytes of the uveal tract, conjunctiva, or orbit; however, up to $50 \%$ of patients will develop metastatic disease [1,2]. Causes of ocular melanoma are unclear, but some possible risk factors include type B ultraviolet radiation, light eye color, ocular melanocytosis, and ubiquitin carboxyl-terminal hydrolase BAP1 mutations [1]. A previously published study using National Cancer Institute's Surveillance, Epidemiology, and End Results Program data examined 4999 cases and found a statistically significant increase of $0.5 \%$ in uveal melanoma (the most common type of ocular melanoma) incidence rates among whites from 1973 to 2013 [3]. The purpose of this study is to provide an update and overview of the incidence of ocular melanoma for the entire United States (US).

We examined population-based cancer registry incidence data from the US Cancer Statistics (USCS) 2001-2016 Public Use Research Database, covering the entire US population [4]. Ocular melanomas were defined by ICD-O3 site code of C69.0-69.6 or C69.8-69.9 and ICD-O-3 histology code of 8720-8790 [4].

Manxia Wu

mwu@cdc.gov

1 Surveillance and Health Services Research Program, American Cancer Society, Atlanta, GA, USA

2 Division of Cancer Prevention and Control, Centers for Disease Control and Prevention, Atlanta, GA, USA

3 Division of Population Health, Centers for Disease Control and Prevention, Atlanta, GA, USA

4 State Center for Health Statistics, Division of Public Health, North Carolina Department of Health and Human Services, Raleigh, NC, USA
We used SEER*Stat software version 8.3.5 to calculate age-adjusted rates per $1,000,000$ population. We examined rates by period (2001-2005, 2006-2010, and 2011-2016), by age group $(0-44,45-54,55+$ years $)$, race/ethnicity, and sex. We examined trends in ocular melanoma incidence rates using joinpoint regression modeling, which fits a series of joined straight lines on a logarithmic scale to the trends in the annual rates [5].

For each period examined, the most commonly diagnosed type of ocular melanoma was choroid (C69.3) (Table 1). Rates were highest among those $\geq 55$, nonHispanic whites, and males (Table 1).

After limiting analysis to non-Hispanic whites, we observed increasing trends in ocular melanoma rates in males and females combined (APC $=1.08 \%)$ and females alone (APC $=1.49 \%$ ) for age group $\leq 44$ years from 2001 to 2016 (Fig. 1), and females alone (APC $=2.76 \%$ ) for age group $\geq 55$ from 2001 to 2007 (Fig. 1). The rates remained stable for the rest (Fig. 1).

Consistent with previous research, cancer of the choroid was the most common type of ocular melanoma $(75 \%$ overall) [3]. Our data allowed examination of rare cancer incidence among all race/ethnicity groups. Non-Hispanic whites had the highest incidence followed by Non-Hispanic American Indian/Alaska Native and Hispanic. Furthermore, there was a modestly higher increasing trend from 2001 to 2016 among non-Hispanic whites compared with previously published trends from 1973 to 2013 (1.08\% vs. $0.5 \%$ ) [3]. Although females comprised a lower percentage of ocular melanoma cases, increasing trends were seen among non-Hispanic white females in the younger and older age groups. These results provide important preliminary information that could be enhanced by future studies about groups that could benefit from prevention efforts, as early detection and treatment might be vital for positive long-term survival [2]. The strength of this study lies in the comprehensive data from USCS, covering $100 \%$ of the US population. However, the results 
Table 1 Tumor and demographic characteristics of ocular melanoma patients in the United States, 2001-2016.

\begin{tabular}{|c|c|c|c|c|c|c|}
\hline & \multicolumn{2}{|l|}{$2001-2005$} & \multicolumn{2}{|l|}{$2006-2010$} & \multicolumn{2}{|l|}{$2011-2016$} \\
\hline & Rate $(95 \% \mathrm{CI})$ & Count $(\%)$ & Rate $(95 \% \mathrm{CI})$ & Count $(\%)$ & Rate $(95 \% \mathrm{CI})$ & Count $(\%)$ \\
\hline Total & $6.46(6.33-6.59)$ & 9454 & $6.31(6.19-6.44)$ & 10,179 & $6.20(6.10-6.31)$ & 13,392 \\
\hline \multicolumn{7}{|l|}{ ICD-O-3 site code } \\
\hline Conjunctiva (C69.0) & $0.39(0.36-0.43)$ & $574(6.1)$ & $0.38(0.35-0.41)$ & $600(5.9)$ & $0.37(0.34-0.39)$ & $776(5.8)$ \\
\hline Cornea NOS (C69.1) & $0.02(0.01-0.03)$ & $31(0.3)$ & $0.02(0.01-0.03)$ & $31(0.3)$ & $0.01(0.01-0.02)$ & $22(0.2)$ \\
\hline Retina (C69.2) & $0.05(0.05-0.08)$ & $93(1.0)$ & $0.05(0.04-0.06)$ & $79(0.8)$ & $0.02(0.01-0.03)$ & $41(0.3)$ \\
\hline Choroid (C69.3) & $4.74(4.63-4.86)$ & $6957(73.6)$ & $4.69(4.59-4.80)$ & $7583(74.5)$ & $4.77(4.67-4.86)$ & $10,334(77.2)$ \\
\hline Ciliary body and iris (C69.4) & $0.66(0.62-0.70)$ & $961(10.2)$ & $0.72(0.68-0.77)$ & $1165(11.4)$ & $0.71(0.67-0.74)$ & $1500(11.2)$ \\
\hline Lacrimal gland (C69.5) & a & a & a & a & $0.01(0.01-0.01)$ & $18(0.1)$ \\
\hline Orbit NOS (C69.6) & $0.08(0.06-0.09)$ & $114(1.2)$ & $0.07(0.06-0.08)$ & $112(1.1)$ & $0.06(0.05-0.07)$ & $135(1.0)$ \\
\hline $\begin{array}{l}\text { Overlapping lesion of eye and } \\
\text { adnexa (C69.8) }\end{array}$ & $0.12(0.10-0.14)$ & $178(1.9)$ & $0.07(0.05-0.08)$ & $106(1.0)$ & $0.04(0.03-0.05)$ & $85(0.6)$ \\
\hline Eye NOS (69.9) & $0.37(0.34-0.41)$ & $546(5.8)$ & $0.31(0.28-0.34)$ & $503(4.9)$ & $0.23(0.21-0.25)$ & $481(3.6)$ \\
\hline \multicolumn{7}{|l|}{ Age } \\
\hline $0-44$ years & $1.33(1.25-1.40)$ & $1201(12.7)$ & $1.31(1.24-1.39)$ & 1165 (11.4) & $1.37(1.30-1.45)$ & $1461(10.9)$ \\
\hline $45-54$ years & 8.33 (7.94-8.74) & $1699(18.0)$ & $7.84(7.48-8.22)$ & $1751(17.2)$ & $7.70(7.37-8.05)$ & $2065(15.4)$ \\
\hline $55+$ years & $20.92(20.41-21.43)$ & $6563(69.4)$ & 20.59 (20.11-21.07) & $7273(71.4)$ & $19.98(19.59-20.39)$ & $9866(73.7)$ \\
\hline \multicolumn{7}{|l|}{ Race and ethnicity ${ }^{b}$} \\
\hline Non-Hispanic white & $7.73(7.57-7.89)$ & $8828(94.2)$ & $7.80(7.64-7.96)$ & $9506(94.4)$ & $7.82(7.68-7.97)$ & $12,256(93.7)$ \\
\hline Non-Hispanic black & $0.55(0.43-0.68)$ & $81(0.9)$ & $0.53(0.43-0.66)$ & $91(0.9)$ & $0.60(0.50-0.71)$ & $135(1.0)$ \\
\hline $\begin{array}{l}\text { Non-Hispanic American Indian/ } \\
\text { Alaska native }\end{array}$ & $3.33(2.10-4.97)$ & $26(0.3)$ & $4.33(3.01-6.01)$ & $39(0.4)$ & $2.36(1.60-3.35)$ & $34(0.3)$ \\
\hline $\begin{array}{l}\text { Non-Hispanic Asian or Pacific } \\
\text { Islander }\end{array}$ & $1.32(1.00-1.69)$ & $67(0.7)$ & $0.73(0.54-0.96)$ & $53(0.5)$ & $1.05(0.86-1.27)$ & $112(0.9)$ \\
\hline Hispanic & $3.27(2.92-3.65)$ & 367 (3.9) & $2.65(2.37-2.95)$ & $377(3.7)$ & $2.40(2.19-2.62)$ & $536(4.1)$ \\
\hline \multicolumn{7}{|l|}{ Sex } \\
\hline Male & $7.46(7.25-7.67)$ & $4950(52.3)$ & $7.11(6.92-7.31)$ & $5264(51.7)$ & $6.96(6.79-7.13)$ & $6996(52.2)$ \\
\hline Female & $5.68(5.51-5.85)$ & $4513(47.7)$ & $5.68(5.52-5.84)$ & $4925(48.3)$ & $5.59(5.45-5.73)$ & $6396(47.8)$ \\
\hline
\end{tabular}

Rates age-adjusted per 1,000,000.

NOS not otherwise specified.

${ }^{a}$ These rates could not be calculated due to fewer than 16 cases.

${ }^{\mathrm{b}}$ Unknown race and ethnicity were excluded.

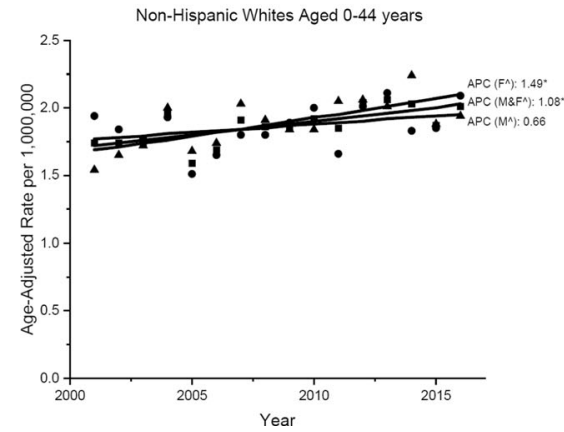

Fig. 1 Ocular melanoma observed (symbols) and joinpoint modeled (lines) rates for non-Hispanic whites by age and sex, 2001-2016. Rates age-adjusted per $1,000,000 .{\mathrm{M} \& \mathrm{~F}^{\wedge}}^{\wedge}$ males and
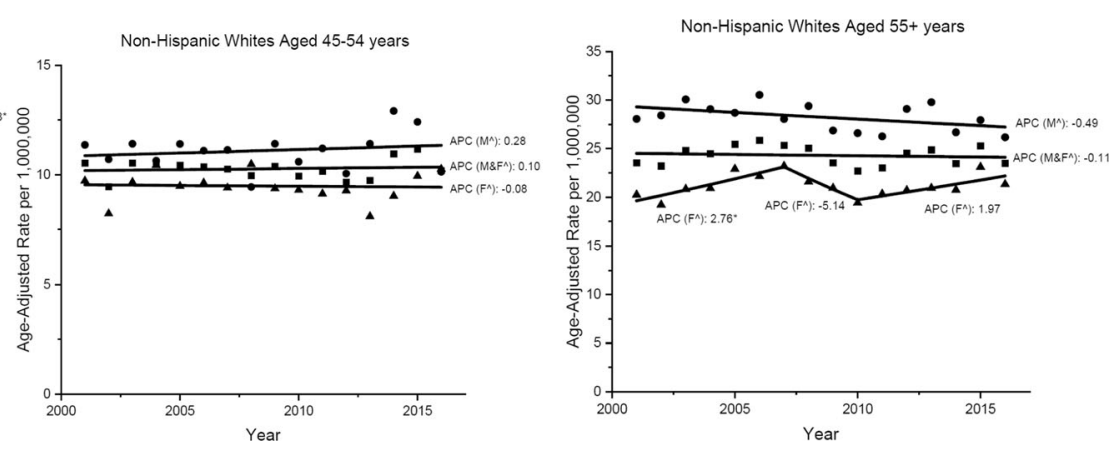

females, $\mathrm{M}^{\wedge}$ males, $\mathrm{F}^{\wedge}$ females. An asterisk indicates that the $t$-test for the annual percent change (APC) had a $p$ value $<0.05$. 
are limited by the rarity of this disease, meaning we were unable to stratify for further geographical analyses or to examine clustering.

Acknowledgements We gratefully acknowledge all cancer registries and their staff for their hard work and diligence in collecting cancer information, without which this research could not have been done.

Funding This project was supported in part by the Intramural Research Department of the American Cancer Society. The American Cancer Society had no role in the design and conduct of the study; collection, management, analysis, and interpretation of the data; preparation, review, or approval of the manuscript; and decision to submit the manuscript for publication. This research was supported in part by an appointment (MBC) to the Research Participation Program at the Centers for Disease Control and Prevention administered by the Oak Ridge Institute for Science and Education through an interagency agreement between the U.S. Department of Energy and the Centers for Disease Control and Prevention. MBC was at the Centers for Disease Control and Prevention when this work began and is now with the Surveillance and Health Services Research Program, American Cancer Society. MBC is employed by the American Cancer Society, which receives grants from private and corporate foundations, including foundations associated with companies in the health sector for research outside the submitted work. The authors are not funded by any of these grants and their salary is solely funded through American Cancer Society funds.

\section{Compliance with ethical standards}

Conflict of interest The authors declare that they have no conflict of interest.

Publisher's note Springer Nature remains neutral with regard to jurisdictional claims in published maps and institutional affiliations.

\section{References}

1. Blum ES, Yang J, Komatsubara KM, Carvajal RD. Clinical management of uveal and conjunctival melanoma. Oncology. 2016;30:29-32. 34-43, 48.

2. Kaliki S, Shields CL. Uveal melanoma: relatively rare but deadly cancer. Eye. 2017;31:241-57.

3. Aronow ME, Topham AK, Singh AD. Uveal melanoma: 5-year update on incidence, treatment, and survival (SEER 1973-2013). Ocul Oncol Pathol. 2018;4:145-51.

4. Fritz A, Percy C, Jack A, Shanmugarathnam K, Sobin L, Parkin D, et al. International classification of diseases for oncology. 3rd ed. Geneva, Switzerland: World Health Organization; 2000. www. who.int/classifications/icd/adaptations/oncology/en/.

5. Kim HJFM, Feuer EJ, Midthune DN. Permutation tests for joinpoint regression with applications to cancer rates. Stat Med. 2000;19:335-51. 